\title{
LUBRICATION OF GEARBOXES: CFD ANALYSIS OF A CYCLOIDAL GEAR SET
}

\author{
FRANCO CONCLI ${ }^{1}$, LORENZO MACCIONI $^{1} \&$ CARLO GORLA $^{2}$ \\ ${ }^{1}$ Faculty of Science and Technology, Free University of Bolzano/Bozen, Italy \\ ${ }^{2}$ Dipartimento di Meccanica, Politecnicodi Milano, Italy
}

\begin{abstract}
In recent years, the increasing demand for more and more compact and efficient solutions has highlighted the need to have appropriate tools in order to optimize the internal design, to avoid thermal problems, ensuring proper lubrication and to increase the reliability of the systems. Typical high power density gearbox designs are based on planetary, harmonic and cycloidal architectures. Although many analytical and numerical models are already available for the prediction of the power losses related to gear meshing (sliding), bearings and seals, literature is lacking in terms of hydraulic power loss models (deep lubrication, churning, windage and squeezing). Some numerical multiphase CFD and experimental studies on parallel axis and planetary gear sets have been already performed by the authors in previous research. The aim of this paper is to extend the applicability of the previously developed numerical techniques to cycloidal architectures, taking into account the typical lubricants used for these type of drives. With respect to the load independent power losses (related to the interaction of the mechanical component and the surrounding lubricant), the cycloidal gear set has been numerically simulated with an especially developed CFD code implemented in the OpenFOAM ${ }^{\circledR}$ environment. A specific mesh handling technique allows us to manage the topological changes of the domain ensuring the numerical stability of the simulation and the correct calculation of the complex multiphase flows that take place in gearboxes. The results have been compared with those already available for other gear architectures with similar performances (dimensions, reduction ratios and loads).
\end{abstract}

Keywords: cycloidal drive, CFD, power losses, efficiency maps, multiphase.

\section{INTRODUCTION}

Nowadays, a big selection of high power density gearboxes are available on the market and, in a business-to-business context, designers could choose the ideal solution based on a series of attributes such as output speed or gear ratio (GR), torque, backlash, overall dimensions, axis orientation, working conditions, cost, efficiency, etc.

Typical competing solutions are: traditional planetary gearboxes, cycloidal architectures and harmonic drives. For high GRs, the most promising architectures seem to be the cycloid and harmonic ones (having the same number of stages) while for low GRs the harmonics are not competitive solutions. For GRs between 30 and 130, cycloidal and harmonic solutions have approximately the same power density [1]. Below a GR of 30, the kinematic of the harmonic drive is not working. In addition, the tolerances required to ensure the correct operation of such solution are of an order of magnitude higher than those needed in cycloidal and planetary gear sets [1]. This affects significantly costs and reliability. For this reason, for GRs between 10 and 30, only planetary and cycloidal architectures can be effectively adopted.

A cycloidal gear has the following main elements: an input shaft with an eccentric cam, a cycloidal disk, an external (fixed) housing with a series of rollers that engaged with the cycloid disk, an output shaft able to extract the rotation motion of the cycloid disk (usually through hole-pin). The input shaft moves the centre of the cycloid disk along a circular trajectory. The cycloidal disk, performing this eccentric motion, engages with the rollers positioned on the external housing. It has an opposite rotating direction with respect the input 
shaft. Holes in the cycloidal disk drag the pins, allowing the output shaft to extract this motion. Since this solution is dynamically unbalanced, additional components or modifications are often introduced, such as, for example, counterweights or an additional cycloidal out of phase $\left(180^{\circ}\right)$ disk.

The GR depend on the number of the cycloidal lobes $Z_{1}$ and the number of rollers $Z_{2}$. It is possible to note how the maximum GR can be achieved when the difference $Z_{2}-Z_{1}=1$. Therefore, this is the solution usually considered when not differently explained.

$$
G R=\frac{\omega_{\text {input }}}{\omega_{\text {output }}}=\frac{Z_{1}}{Z_{2}-Z_{1}}
$$

From a theoretical point of view, in a cycloidal gear set, each pin is in contact with the corresponding lobe, but only half of the rollers transfer forces [2]. However, the presence of backlash between rollers and cycloidal disk (for compensating manufacturing tolerances and to guarantee better lubrication and mounting conditions [3], causes that not all the engaged flanks transmit the theoretical load. A numerical and experimental analysis of a cycloidal reducer with a single contact lobe-roll (to simulate the worst use condition) was presented by Sensinger and Lipsey [1]. It is shown that the maximum stress occurs in the contact point between the lobe and the roller. Indeed, cycloidal profiles present only compression stresses, thus ensuring a better resistance to overloads (up to 500\%). The investigations have also shown that just in the contact areas where the force has the maximum value, the equivalent curvature has its maximum value and this is exceptionally favourable from the point of view of the loading capacity of the cycloidal disk.

However, the efficiency of a cycloidal gear is generally not a competing factor compared with traditional planetary solutions.

\section{POWER LOSSES OF GEARS}

The power losses in geared transmissions can be classified, according to Niemann, into load dependent and load independent one (sub-index $\left.\right|_{0}$ ). The load dependent power losses are proportional to the transmitted torque, while the load independent one are not directly related to the load. However, the level of torque affects the operating temperatures and the lubricant properties (density and mostly viscosity) having an influence also on the so-called load independent power losses. A further classification can be made according to the mechanical component that generates the losses:

$$
P_{L}=P_{L G}+P_{L G 0}+P_{L B}+P_{L B 0}+P_{L S}+P_{L X} .
$$

The sub-indexes $\left.\right|_{G},\left.\right|_{B},\left.\right|_{S}$ and $\left.\right|_{X}$ stand for gears, bearings, seals and other generic components respectively.

In the years, several authors have published experimentally derived or analytical results for most of the losses. The load dependant power losses of gears $\left(P_{L G}\right)$ are due to sliding in the contact. The ISO 6336 standard [4] provides an accurate model to predict such component of the losses. Examples of particular designs with improved meshing efficiency have been shown [5]-[7].

Several research activities were carried out for what concerns the bearing losses. The SKF model [8] or the Schaeffler [9] one, for example, provide accurate results both for the load dependant $\left(P_{L B}\right)$ and for the load independent $\left(P_{L B 0}\right)$ power losses of bearings. For the seal losses $\left(P_{L S}\right)$, a general method is shown in [10]. What is still missing is a general method for the prediction of the load independent power losses of gears $\left(P_{L G 0}\right)$.

In the past, several authors proposed empirical models based on experimental evidences. Daily and Nece [11] and Mann and Marston [12] proposed models for the churning losses of 
smooth discs. These results were extended by Ohlendorf [13] who proposed the first churning model for a (single) gear. The next improvement was done by Richter [14]. Its model is the first that take into consideration the mutual effect of two meshing gears. Terekhov [15] performed systematic research in order to understand the influence of the rotational speed, the module, the immersion depth, the gear diameter, the tooth face width, the gear ratio and the oil viscosity on the churning and squeezing power losses for splash lubricated gears. The formulation proposed by Terekhov was improved by Walter and Langenbeck [16] and Walter [17]. One of the most complete empirical models was published in 1975 by Mauz [18]. More recent experimental studies were performed by Diab et al. [19] and Höhn et al. [20]. However, all these models are applicable only to spur gears and for a limited range of operating conditions. The limitations of the empirical models have been overcome with the introduction, in the recent years, of the computational fluid dynamic and the recent development in computer science. The first numerical works were presented by Diab et al. [19] and Marchesse et al. [21]. Further studies were performed by Gorla et al. [22], [23] and Concli et al. [24]. The main limitation of the numerical models is related to the computational effort required. Some research was conducted by the author in order to improve the computational efficiency of the numerical methods [25], [26]. SPH based methods were presented by Groenenboom et al. [27], Liu et al. [28], Ji et al. [29], Shi et al. [30], Rahmatjan and Geni [31], Imin and Geni [32], Zhigang et al. [33] and Liu et al. [34]. A review article showing advantages and limitation of all the available models was presented by Concli and Gorla [35].

This lack of literature, valid for gears in general, is even more noticeable for cycloidal architectures, where the sources of loss are due to friction of bearings (on the eccentric input shaft), friction between the rollers and the cycloidal disk, friction in the holes-pins contacts (or any solution adopted to extract the motion from the cycloidal disk) and hydraulic losses.

Although the first three points of the bullet list have been widely discussed in the literature, the hydraulic losses have not been studied at all.

\section{FV APPROACH}

In the past some authors have already studied the lubrication of planetary gearboxes with a finite volume (FV) approach [36]-[43]. In this study, the already presented global remeshing method (GRA) [44] was applied to a cycloidal gear-set.

The solver adopted is a solver for 2 incompressible fluids, which captures the interface using a VOF method with optional mesh motion. It relies on the numerical solution of a mass and a momentum conservation equation:

$$
\begin{gathered}
\frac{\partial \rho}{\partial t}+\nabla \cdot(\rho \boldsymbol{v})=0 \\
\frac{\partial(\rho \boldsymbol{v})}{\partial t}+\nabla \cdot(\rho \boldsymbol{v} \boldsymbol{v})=-\nabla p+\nabla \cdot\left[\mu\left(\nabla \boldsymbol{v}+\nabla \boldsymbol{v}^{T}\right)\right]+\rho \boldsymbol{g}+\boldsymbol{F},
\end{gathered}
$$

where $\rho$ is the density, $\boldsymbol{v}$ is the velocity vector, $\mu$ is the viscosity of the lubricant, $\boldsymbol{g}$ is the gravitational acceleration and $\boldsymbol{F}$ represents the external forces. These equations are applied to each cell of the computational grid. The solution of the system is performed with a PIMPLE (merged PISO-SIMPLE) algorithm. This conjugate the advantages in terms of computational efficiency of the SIMPLE scheme with the capability of the PISO one to be time-conservative.

An additional equation is used to take into account the presence of two phases (air and lubricant): 


$$
\frac{\partial}{\partial t} \alpha+\frac{\partial}{\partial x_{i}}\left(\alpha u_{i}\right)=0
$$

where $\alpha$ is a scalar called volume fraction. The averaged properties $(\phi)$ of the mixture in each cell of the domain are calculated as an $\alpha$-averaged value of the properties of air and lubricant:

$$
\phi=\phi_{\text {lub }} \cdot \alpha+\phi_{\text {air }} \cdot(1-\alpha) \text {. }
$$

\section{MESH HANDLING}

In CFD simulations of gearboxes, the computational domain intrinsically changes its topology during the calculation. This implies a severe mesh distortion and the need to update the grid after few time steps. In the past, the authors have used commercial software capable to handle automatically the grid update. Even if this approach is effective, it is not efficient. The user, in fact, loses the control of the mesh size and element shape. Small cells were inevitably produced and this causes a significant increment in the computational effort required, not so much for the increased number of elements, but for the need, in order to ensure the stability of the solution, to reduce drastically the time step (to keep the Co number equal to 1). The authors have shown how, with the so called global remeshing approach (GRA) [45], it is possible to have a much higher control of the grid parameters, ensuring huge time savings for the computation thanks to the bigger possible time steps.

The grid is regenerated completely after few time steps (Fig. 1) and the results of the previous computation mapped on the new mesh.
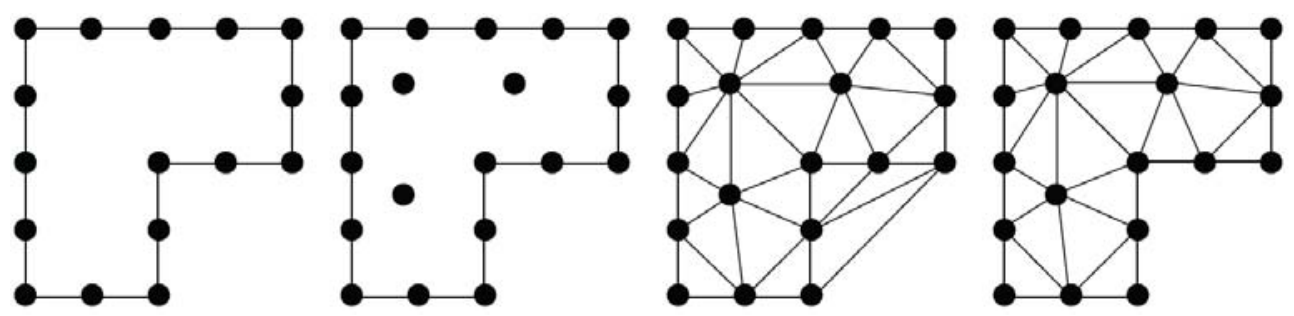

Figure 1: Steps performed by the Delaunay algorithm [45].

In OpenFOAM ${ }^{\circledR}$ two meshing tools are available. BlockMesh, is capable of creating parametric structured grids but is not suitable to handle complex geometries. The second tool, SnappyHexMesh, is capable to generate 3-dimensional grids starting from triangulated surface geometries. The grid approximately conforms to the surface by iteratively refining a starting structured grid and morphing the resulting split-hex mesh to the surface. This approach is robust but also very time consuming and not suitable for the purposes of this study.

For this reason, the grid (2-dimensional) was created following a top down strategy that starts by computing the corner points, and discretize the edges and the faces with an advancing front surface mesh generator. A fast Delaunay algorithm generates the mesh.

Eventually it fails for the last elements, back-tracking rule based algorithm takes over [39], [46]. The Delaunay algorithm subdivides the edges into segments according to the local seed prescribed element size. The faces are seeded with points. These are connected together during the so-called triangulation phase. If the results of the triangulation is a grid that exceed the boundaries, the protruded elements are removed. 
Fig. 2 shows the flow chart of the GRA. A first mesh is generated and the simulation performed up to the point in which the quality pf the grid becomes lower than a threshold. At this point a new grid is generated starting from the topology of the domain of the previous time step. The results are mapped on the new grid. The simulation restarts. The procedure is repeated up to when the last time step is reached.

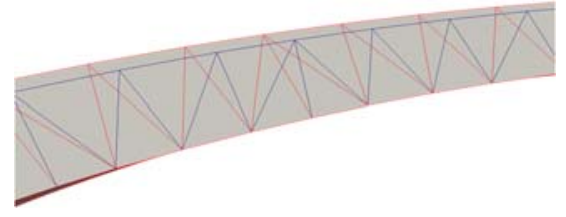

(a)

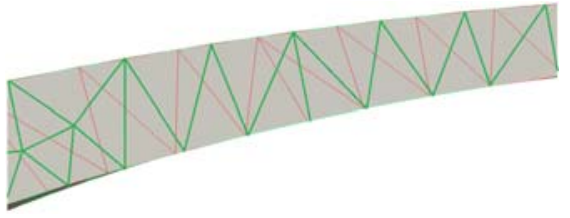

(b)

Figure 2: $\quad$ Example of mesh update. (a) Grid before the deformation (blue) and after several time steps (red); and (b) Deformed mesh of the previous time step (red) and new mesh (green).

\section{CYCLOIDAL GEAR SET}

The profile of a cycloidal gear set, with a unitary difference between number of rollers and number of lobes, can be expressed by the coordinates $C_{x}$ and $C_{y}$ (with the origin in the centre of the cycloid) as function of the parameter $\phi$ (angle of input shaft) that can vary between 0 and $2 \pi$.

$$
\begin{gathered}
C_{x}=\mathrm{R} \cdot \cos (\phi)-R_{r} \cdot \cos (\phi+\psi)-\mathrm{e} \cdot \cos \left(\left(Z_{1}+1\right) \cdot \phi\right), \\
C_{y}=-\mathrm{R} \cdot \sin (\phi)+R_{r} \cdot \sin (\phi+\psi)+\mathrm{e} \cdot \sin \left(\left(Z_{1}+1\right) \cdot \phi\right), \\
\text { where } \psi=\tan ^{-1}\left(\frac{\sin \left(Z_{1} \cdot \phi\right)}{\cos \left(Z_{1} \cdot \phi\right)-\frac{\mathrm{R}}{\mathrm{e} \cdot\left(Z_{1}+1\right)}}\right),
\end{gathered}
$$

where $\mathrm{R}$ is the distance between the centre of each roller and the input shaft axis, $R_{r}$ is the radius of rollers, $e$ is the eccentricity of the input shaft and $Z_{1}$ is the number of lobes of the cycloid (one less of the number of rollers in this case) [47].

With the aim of comparing the numerical hydraulic losses of a traditional planetary gearset (already studied in [36]) with a potentially competing cycloidal gear set, geometrical data were chosen in order to have the same gear ratio, comparable dimensions and same nominal torque.

$$
R=40 \mathrm{~mm} ; R_{r}=5 \mathrm{~mm} ; e=2 \mathrm{~mm} ; Z_{1}=10
$$

A radial gap of $0.1 \mathrm{~mm}$ was selected. The pin-hole connection and any additional balancing cycloid were not considered.

\section{RESULTS AND DISCUSSION}

Simulations were performed with a 2D model. The lateral backlashes between the internal shaft and the external housing were not modelled. This is an acceptable assumption if the axial width of the gear-set is significant. The meshing between the two cycloids (internal and external ones) produces a significant pumping effect [48]-[50]. This can be observed in Figs 3-5. The volume between two lobes reduces suddenly causing an overpressure in the gap (Fig. 6). Part of the lubricant in squeezed out. The successive opening of the gap 
(separation of the surfaces belonging to the internal and the external cycloids) causes a successive pressure decrease (Fig. 7). Vortices take place. The circulation involves mainly the region filled with air while the lubricant seem to have a laminar flow.

The pressure is constant in each gap.

Similar squeezing/pocketing effects were observed for planetary gears, but only near the meshing region (Fig. 8). The much bigger open spaces in a traditional planetary configuration, promote a better circulation of the lubricant and the pumping effects results reduced with respect to the cycloidal gear set.

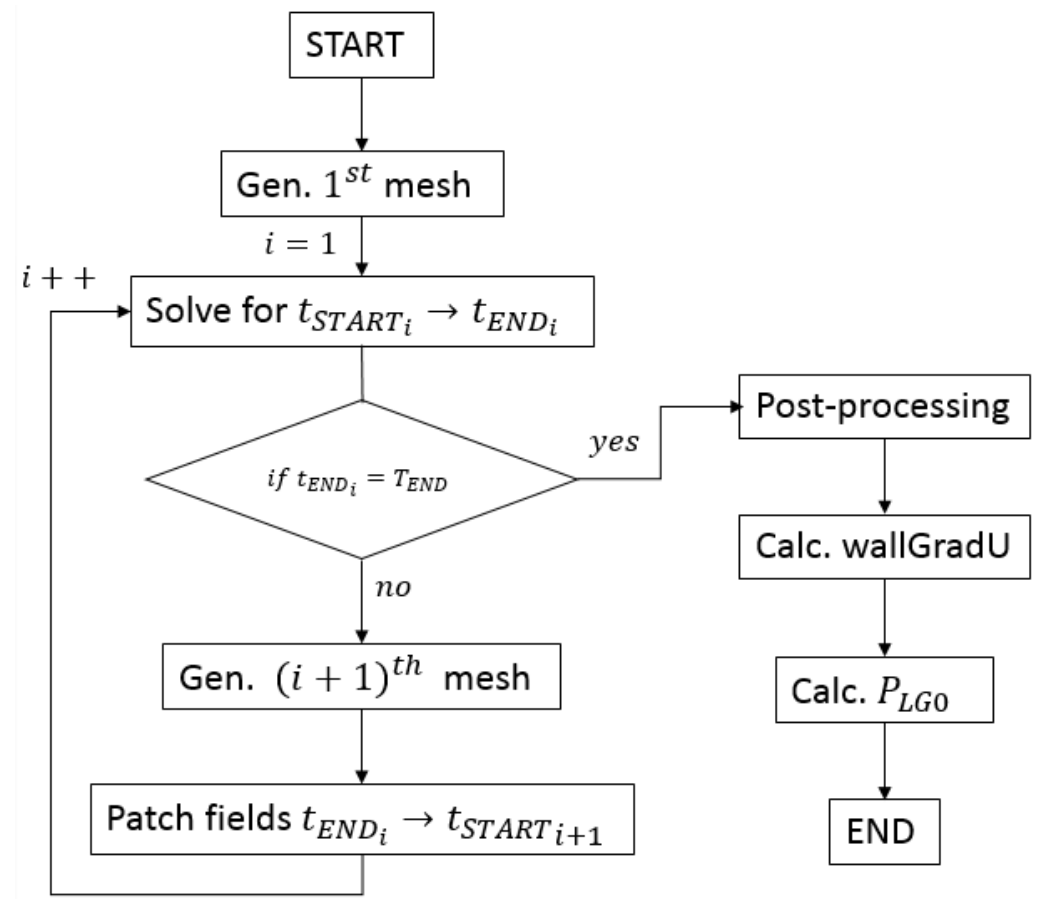

Figure 3: Flow chart of the GRA.

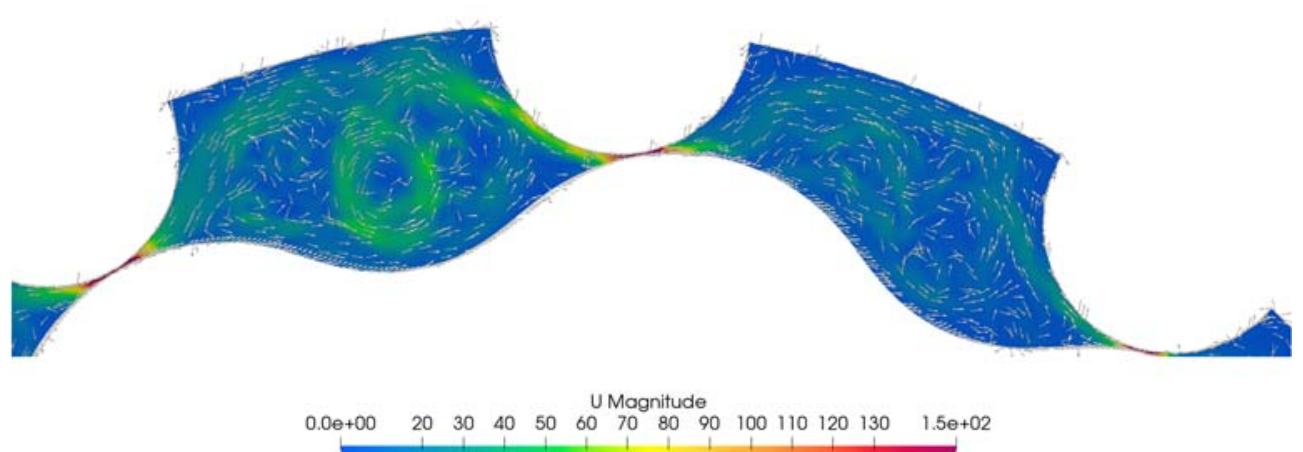

Figure 4: Velocity contour plot and oil distribution. 

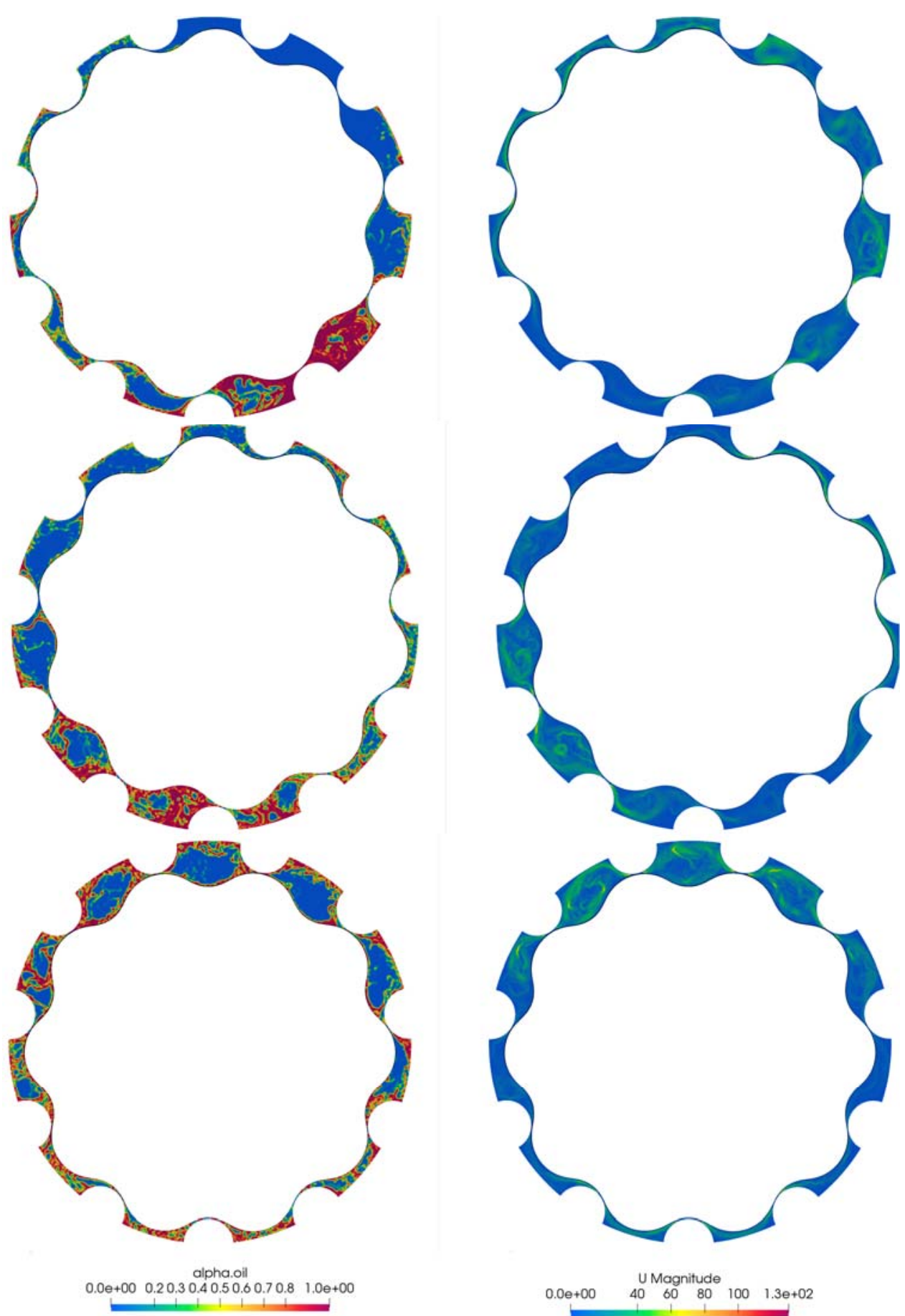

Figure 5: Details of the circulation effects: on the right a gap that is closing, on the left a gap that is opening. The squeezing effect can be clearly observed. 

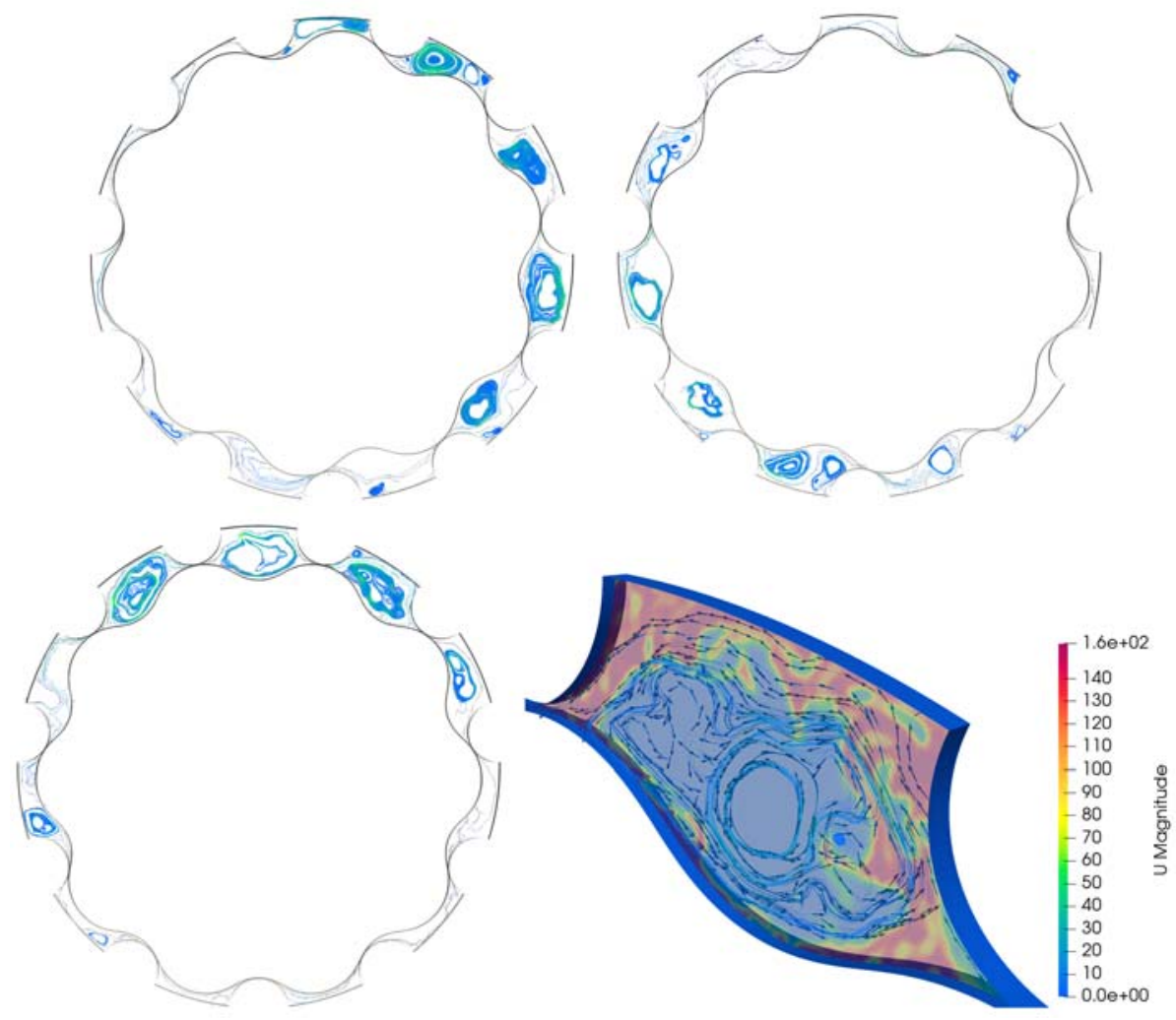

Figure 6: Streamlines and oil volume fraction contour.

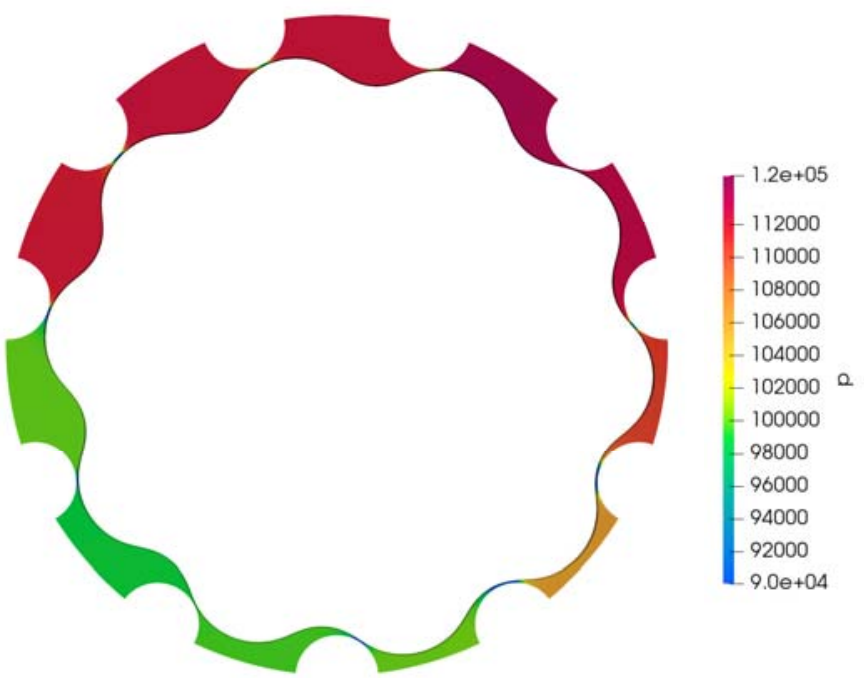

Figure 7: Pressure distribution in the different gaps. 

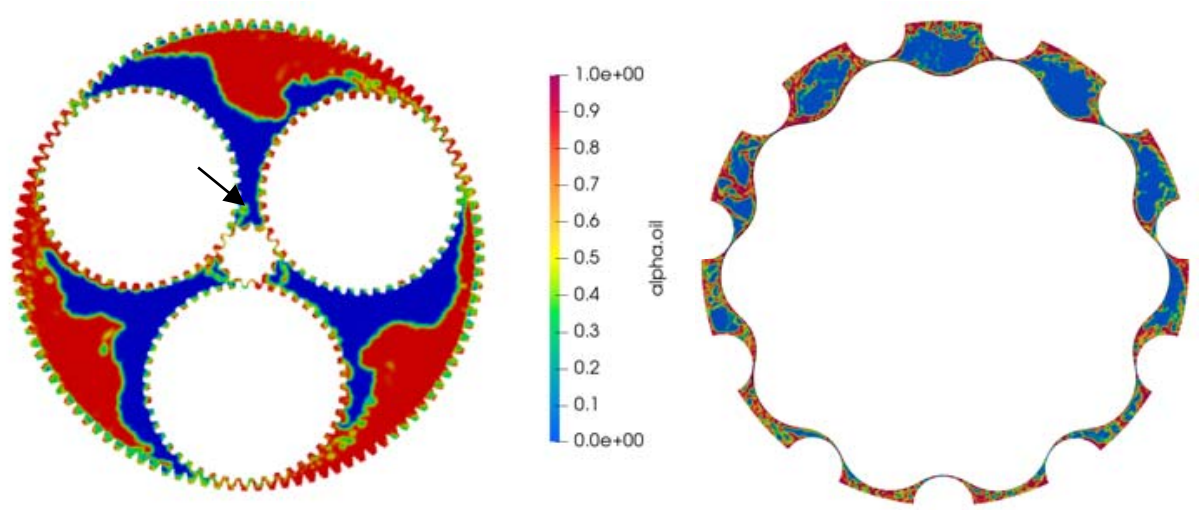

Figure 8: Comparison between a traditional planetary gear-set [6] and a cycloidal configuration (reduction ratio 10).

\section{COMPUTATIONAL EFFORT}

This preliminary simulation was performed on a single core 9.6GFLOP hardware. The simulation took approximately 3 days to perform a complete rotation of the internal cycloid.

\section{CONCLUSIONS}

The present paper reports some preliminary results concerning the lubrication of a cycloidal gear set. The adopted model is $2 \mathrm{D}$. This implies that the axial flows were neglected. This assumption is acceptable if the axial with of the gears is significantly higher with respect to the lateral backlash. Beside the geometrical simplifications, the proposed approach has allowed the simulation of a complex kinematic in a reasonable amount of time, ensuring a very stable numerical convergence. Based on this promising results, the presented numerical approach will be extended and used for deeper studies of the lubrication of cycloidal gear sets.

The $2 \mathrm{D}$ results have shown that while in planetary gear sets, the main load independent power losses of gears are due to churning (of the planet carrier and planets), in cycloidal configurations, significant pumping/squeezing effect took place in the gaps near the meshing region due to sudden variations of the volumes and high pressure gradients. Vortices appears, especially in the opening gaps (where the lubricant/air mixture is squeezed from the previous gap that is reducing its volume). These vortices involve mainly the air while the lubricant flux seems to be laminar $(R e<2 \mathrm{E} 3)$.

\section{REFERENCES}

[1] Sensinger, J.W. \& Lipsey, J.H., Cycloid vs. harmonic drives for use in high ratio, single stage robotic transmissions. 2012 IEEE Int. Conf. Robot. Autom., pp. 41304135, 2012.

[2] Gorla, C., Davoli, P., Rosa, F., Longoni, C., Chiozzi, F. \& Samarani, A., Theoretical and experimental analysis of a cycloidal speed reducer. J. Mech. Des. Trans. ASME, 130(11), pp. 1126041-1126048, 2008.

[3] Blagojevic, A. et al., Numerical and experimental analysis of the cycloid disc stress state. Tech. Gaz., 21(2), pp. 337-382, 2014.

[4] ISO 6336, 2006. 
[5] Xia, Y. et al., A new topology of CMG for high torque and low loss. 2016 Prog. Electromagn. Res. Symp. PIERS 2016 - Proc., 65(11-12), pp. 78-82, 2016.

[6] Concli, F., Low-loss gears precision planetary gearboxes: Reduction of the load dependent power losses and efficiency estimation through a hybrid analyticalnumerical optimization tool. Forsch. im Ingenieurwesen/Engineering Res., 2017.

[7] Anderson, N.E. \& Loewenthal, S.H., Design of spur gears for improved efficiency. $J$. Mech. Des. Trans. ASME, 104(4), pp. 767-774, 1982.

[8] www.SKF.com.

[9] www.schaeffler.it.

[10] Niemann, G. \& Winter H., Maschinenelemente, 2005.

[11] Daily, J.W. \& Nece, R.E., Chamber dimension effects on induced flow and frictional resistance of enclosed rotating disks. J. Fluids Eng. Trans. ASME, 82(1), pp. 217-230, 1960.

[12] Mann, R.W. \& Marston, C.H., Friction drag on bladed disks in housings as a function of reynolds number, axial and radial clearance, and blade aspect ratio and solidity. $J$. Fluids Eng. Trans. ASME, 83(4), pp. 719-723, 1961.

[13] Ohlendorf, H., Verlustleistung und Erwärmung von Stirnrädern, 1958.

[14] Richter, W., Stirnradgetriebe, Zahnreibung, Verlustleistung und Erwärmung, 1964.

[15] Terekhov, A.S., Hydraulic losses in gearboxes with oil immersion. Russ. Eng. J., 55(5), pp. 7-11, 1975.

[16] Walter, P. \& Langenbeck, K., Anwendungegrenzen für die Tauchschmierung von Zahnradgetrieben, Plansch- und Quetschverluste bei Tauchschmierung, 1982.

[17] Walter, P., Untersuchung Zur Tauchschmierung Von Stirnrädern Bei Umfangsgeschwindigkeiten Bis 60 M/S, 1982.

[18] Mauz, W., Hydraulische Verluste von Strinradgetrieben bei Umfansgsgeschwindigkeiten bis $60 \mathrm{~m} / \mathrm{s}$. Hydraul. Verluste von Stirnradgetrieben Bei Umfangsgeschwindigkeiten Bis 60 M/s, 1987.

[19] Diab, Y., Ville, F., Velex, P. \& Changenet, C., Windage losses in high speed gearspreliminary experimental and theoretical results. J. Mech. Des. Trans. ASME, 126(5), pp. 903-908, 2004.

[20] Höhn, B.-R., Michaelis, K. \& Otto, H.-P., Influence on no-load gear losses. Ecotrib. 2011 Conf. Proc., 2, pp. 639-644, 2011.

[21] Marchesse, Y., Changenet, C., Ville, F. \& Velex, P., Investigations on CFD simulations for predicting windage power losses in spur gears. J. Mech. Des. Trans. ASME, 133(2), 2011.

[22] Gorla, C. et al., Hydraulic losses of a gearbox: CFD analysis and experiments. Tribol. Int., 66, 2013.

[23] Gorla, C. et al., CFD simulations of splash losses of a gearbox. Adv. Tribol., 2012.

[24] Concli, F. et al., Load independent power losses of ordinary gears: Numerical and experimental analysis. 5th World Tribology Congress, WTC 2013, 2, 2013.

[25] Concli, F., Gorla, C., Della Torre, A. \& Montenegro, G., Windage power losses of ordinary gears: Different CFD approaches aimed to the reduction of the computational effort. Lubricants, 2(4), pp. 162-176, 2014.

[26] Concli, F., Gorla, C., Della Torre, A. \& Montenegro, G., Churning power losses of ordinary gears: A new approach based on the internal fluid dynamics simulations. Lubr. Sci., 27(5), 2015.

[27] Groenenboom, P.H.L., Mettichi, M.Z. \& Gargouri, Y., Simulating oil flow for gearbox lubrication using smoothed particle hydrodynamics. Proc. Int. Conf. Gears 2015, 2015. 
[28] Liu, Z., Shen, Y. \& Rinderknecht, S., Theoretical and experimental investigation on power loss of vehicle transmission synchronizers with spray lubrication. SAE Tech. Pap., 2019(January), 2019.

[29] Ji, Z., Stanic, M., Hartono, E.A. \& Chernoray, V., Numerical simulations of oil flow inside a gearbox by Smoothed Particle Hydrodynamics (SPH) method. Tribol. Int., 127, pp. 47-58, 2018.

[30] Shi, Y., Li, S., Chen, H., He, M. \& Shao, S., Improved SPH simulation of spilled oil contained by flexible floating boom under wave-current coupling condition. J. Fluids Struct., 76, pp. 272-300, 2018.

[31] Rahmatjan, I. \& Geni, M., SPH algorithm for proper meshing and coupling contact of gears. Zhendong yu Chongji/Journal Vib. Shock, 34(12), pp. 65-69, 2015.

[32] Imin, R. \& Geni, M., Stress analysis of gear meshing impact based on SPH method. Math. Probl. Eng., 2014, 2014.

[33] Zhigang, Y., Imin, R. \& Geni, M., Study on the gear modeling in SPH analysis. Adv. Mater. Res., 33-37, pp. 773-778, 2008.

[34] Liu, H. et al., Numerical modelling of oil distribution and churning gear power losses of gearboxes by smoothed particle hydrodynamics. Proc. Inst. Mech. Eng. Part J J. Eng. Tribol., 233(1), pp. 74-86, 2019.

[35] Concli, F. \& Gorla, C., Windage, churning and pocketing power losses of gears: Different modeling approaches for different goals (Wirkungsgrad und Verluste von Zahnradgetrieben: Verschiedene Methoden für verschiedene Anwendungen). Forsch. im Ingenieurwesen/Engineering Res., 80(3-4), pp. 85-99, 2016.

[36] Concli, F. \& Gorla, C., Numerical modeling of the churning power losses in planetary gearboxes: An innovative partitioning-based meshing methodology for the application of a computational effort reduction strategy to complex gearbox configurations. Lubr. Sci., 2017.

[37] Concli, F. \& Gorla, C., CFD simulation of power losses and lubricant flows in gearboxes. American Gear Manufacturers Association Fall Technical Meeting 2017, 2017.

[38] Concli, F., Conrado, E. \& Gorla, C., Analysis of power losses in an industrial planetary speed reducer: Measurements and computational fluid dynamics calculations. Proc. Inst. Mech. Eng. Part J J. Eng. Tribol., 228(1), 2014.

[39] Concli, F., Thermal and efficiency characterization of a low-backlash planetary gearbox: An integrated numerical-analytical prediction model and its experimental validation. Proc. Inst. Mech. Eng. Part J J. Eng. Tribol., 230(8), 2016.

[40] Drewniak, J., Kopec, J. \& Zawislak, S., Kinematical and efficiency analysis of planetary gear trains by means of various graph-based approaches. Mech. Mach. Sci., 34, pp. 263-284, 2016.

[41] Yin, H.B., Li, S.L., Zhang, H., Zhao, X.Y. \& Zhang, J., The power loss and efficiency analysis of a 3DOFs planetary gear box. Adv. Mater. Res., 834-836, pp. 1285-1289, 2013.

[42] Concli, F. \& Gorla, C., Computational and experimental analysis of the churning power losses in an industrial planetary speed reducer. WIT Transactions on Engineering Sciences, vol. 74, WIT Press: Southampton and Boston, 2012.

[43] Gorla, C. \& Concli, F., Influence of lubricant temperature, lubricant level and rotational speed on the churning power loss in an industrial planetary speed reducer: Computational and experimental study. Int. J. Comput. Methods Exp. Meas., 1(4), pp. 353-366, 2013. 
[44] Concli, F. \& Gorla, C., Numerical modeling of the power losses in geared transmissions: Windage, churning and cavitation simulations with a new integrated approach that drastically reduces the computational effort. Tribol. Int., 103, 2016.

[45] Concli, F., Della Torre, A., Gorla, C. \& Montenegro, G., A new integrated approach for the prediction of the load independent power losses of gears: Development of a mesh-handling algorithm to reduce the CFD simulation time. Adv. Tribol., 2016, 2016.

[46] Schöberl, J., An advancing front 2D/3D-mesh generator based on abstract rules. Comput. Vis. Sci., 1(1), pp. 41-52, 1997.

[47] Sensinger, J.W., Unified approach to cycloid drive profile, stress, and efficiency optimization. J. Mech. Des. Trans. ASME, 132(2), pp. 245031-245035, 2010.

[48] Concli, F. \& Gorla, C., Oil squeezing power losses in gears: A CFD analysis. WIT Transactions on Engineering Sciences, vol. 74, WIT Press: Southampton and Boston, 2012.

[49] Concli, F. \& Gorla, C., Analysis of the oil squeezing power losses of a spur gear pair by mean of CFD simulations. ASME 2012 11th Biennial Conference on Engineering Systems Design and Analysis, ESDA 2012, 2, 2012.

[50] Gorla, C. \& Concli, F., A CFD analysis of the oil squeezing power losses of a gear pair. Int. J. Comput. Methods Exp. Meas., 2(2), pp. 157-167, 2014. 